\title{
Probabilistic and fuzzy fault-tree analyses for modelling cave-in accidents
}

\author{
H. M. Al-Humaidi \\ Kuwait University, Kuwait
}

\begin{abstract}
Construction injury accidents result from different causes. Risk evaluation for cave-ins using traditional fault-tree analysis can be difficult, especially since the variables resulting in cave-ins are unique; in addition, historical data, when available, is often incomplete. In construction, assessment of risk is based on linguistic terms using subjective judgment of linguistic values such as severe, very likely, etc. Such linguistic terms are best modeled using fuzzy set theory. The traditional FTA method has been widely used to calculate the probability of the top undesired event, which is based on historical data of the occurrence and the severity of the basic events. FTA implementation into construction projects needs to be modified since assessment of contributing events to cave-in accidents is based on managerial experience using experiential subjective expressions. This paper introduces a fuzzy triangular model to assess risks associated with excavation work in advance and helps management prepare solutions in advance. Keywords: Fuzzy Logic, fuzzy set, probabilistic fault-tree analysis, fuzzy faulttree analysis, cave-in accidents, construction safety.
\end{abstract}

\section{Introduction}

Cave-in is the collapse of unsupported trench or tunnel soil edges that take place during excavation. Cave-in accidents result from numerous causes, including management and worker actions, support-system materials, equipment control, weather and natural disasters. These antecedents are categorized into procedural, triggering and enabling causes. Procedural causes are indirect; they impact the frequency of cave-in occurrences because they result in enabling or triggering causes separately or together. Procedural causes arise from management and control issues. Examples of management-related procedural causes are poor 
quality control, failure to enforce safety standards, selection of contractors with inadequate safety knowledge or experience, and failure to address safety issues in contract documents. Control-related issues result in both enabling and triggering causes of cave-ins. The presence, level of knowledge and experience of a competent person is essential to control trenching operations. Enabling causes may be internal factors linked to the worker, such as the worker's knowledge, skills and experience, personality, health, working under the influence of medication, illicit drugs or alcohol; or problems related to the design and construction of shoring, shielding and sloping. These latter are further divided into inadequate components, and violation of rules and regulations of excavation. Inappropriate installation or dismantling of support systems is another enabling cause related to shoring or shielding. Triggering causes are external; they are related to such issues as equipment and weather. Equipmentrelated causes are due to surcharge load, vibration, or impact of equipment on the shoring or shielding system. Weather-related issues such as extremes of temperature or rain can cause failure of the support system and trigger cave-in accidents. Major causes of cave-in accidents and their classification into procedural, enabling and triggering causes are illustrated in Table 1.

Table 1: Classification of cave-in causes into procedural, enabling and triggering causes.

\begin{tabular}{|c|c|c|c|c|c|c|}
\hline \multicolumn{2}{|c|}{ Procedural Causes } & \multicolumn{3}{|c|}{ Enabling Causes } & \multicolumn{2}{|c|}{ Triggering Causes } \\
\hline \multicolumn{7}{|c|}{ Causes of Cave-in Related to: } \\
\hline Management & Control & Workers & $\begin{array}{l}\text { Shoring, } \\
\text { Shielding and } \\
\text { Sloping }\end{array}$ & Design & Equipment & Weather \\
\hline $\begin{array}{l}\text { Poor Quality } \\
\text { Control }\end{array}$ & $\begin{array}{l}\text { Absence of } \\
\text { Competent } \\
\text { Person }\end{array}$ & $\begin{array}{l}\text { Inadequate } \\
\text { Knowledge }\end{array}$ & $\begin{array}{l}\text { Inadequate } \\
\text { Components }\end{array}$ & $\begin{array}{l}\text { Inadequate Soil } \\
\text { Investigation }\end{array}$ & $\begin{array}{l}\text { Equipment } \\
\text { Surcharge Load }\end{array}$ & $\begin{array}{l}\text { Extreme } \\
\text { Hot } \\
\text { Weather }\end{array}$ \\
\hline $\begin{array}{l}\text { Lack of } \\
\text { Standards }\end{array}$ & $\begin{array}{l}\text { Knowledge } \\
\text { of } \\
\text { Competent } \\
\text { Person }\end{array}$ & $\begin{array}{l}\text { Inadequate } \\
\text { Skills and } \\
\text { Experience }\end{array}$ & $\begin{array}{l}\text { Violation of } \\
\text { Excavation } \\
\text { Rules and } \\
\text { Practices } \\
\end{array}$ & $\begin{array}{l}\text { Errors in the } \\
\text { Design of } \\
\text { Shoring/Shielding } \\
\text { or Sloping }\end{array}$ & $\begin{array}{l}\text { Equipment } \\
\text { Vibration and } \\
\text { Impact }\end{array}$ & $\begin{array}{l}\text { Extreme } \\
\text { Cold } \\
\text { Weather }\end{array}$ \\
\hline $\begin{array}{l}\text { Improper } \\
\text { Contractor } \\
\text { Selection }\end{array}$ & $\begin{array}{l}\text { Inadequate } \\
\text { Inspection of } \\
\text { Support } \\
\text { Structure }\end{array}$ & $\begin{array}{l}\text { Negative } \\
\text { Personality }\end{array}$ & $\begin{array}{l}\text { Inappropriate } \\
\text { Installation or } \\
\text { Dismantling }\end{array}$ & $\begin{array}{l}\text { Errors in } \\
\text { Selection of } \\
\text { Shoring/Shielding } \\
\text { and Sloping }\end{array}$ & & Rain \\
\hline \multirow[t]{2}{*}{$\begin{array}{l}\text { Improper } \\
\text { Safety } \\
\text { Addressed in } \\
\text { Contract } \\
\text { Documents } \\
\end{array}$} & & Poor Health & $\begin{array}{l}\text { Missing } \\
\text { Support System }\end{array}$ & & & \\
\hline & & $\begin{array}{l}\text { Influence of } \\
\text { Medication, } \\
\text { Illicit Drugs, } \\
\text { or Alcohol }\end{array}$ & & & & \\
\hline
\end{tabular}

\section{Probabilistic fault-tree analysis model}

In general, it is desirable to calculate the likelihood of cave-in accidents in order to avoid them. The cave-in is the top undesired event. The probability of its occurring can be calculated using the probabilistic fault-tree analysis model. In this model, the various causes that contribute to cave-in accidents are assumed to 
be independent. The degree of effectiveness each factor has on the overall likelihood of a cave-in accident is quantified using a probabilistic value that ranges from 0 to 1 .

Each factor affects the overall likelihood of a cave-in accident (top undesired event) with a certain degree of effectiveness. For example, bad weather conditions may be expected, and the probability of bad weather (probability of rain) can be determined from weather reports. This factor is conditioned on the degree of effectiveness of bad weather on the overall likelihood of a cave-in accident. An INHIBIT gate is used to condition each cause on its effectiveness on the likelihood of a cave-in accident. Two gates are implemented to link basic events, the AND gate and the OR gate. Fig. 1 below shows the logic implemented in constructing a probabilistic fault-tree analysis.

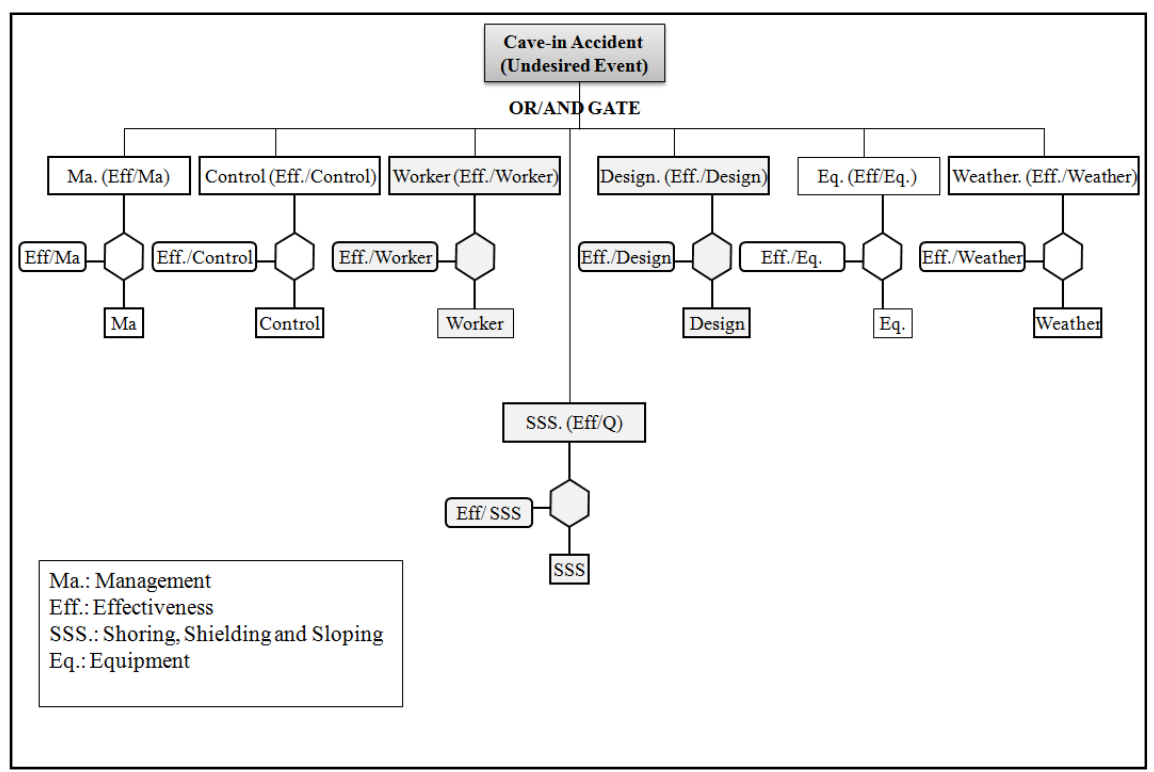

Figure 1: Probabilistic fault-tree logic.

Fault-tree analyses are generally performed graphically using a logical structure of AND, OR, and INHIBIT gates [4]. Basic events may occur together causing the top event to occur. In this case, these events would be arranged under an AND gate, meaning that all of the basic events would need to occur to trigger the top event. Certain basic events would trigger the top undesired event alone; these basic events are grouped under an OR gate. If a basic event (event A) triggers the top undesired event when it is conditioned on the occurrence of another event (event B), a conditional failure occurs since the occurrence of (event $\mathrm{A}$ ) is conditioned on the occurrence of (event B). In such conditional occurrence of events, an INHIBIT gate is used [4]. Assuming that all events are statistically independent, the probability of the top undesired event (cave-in accident) can be calculated as follows: 


$$
\mathrm{P}(\mathrm{Top})=\mathrm{P}(\mathrm{A}) \cap \mathrm{P}(\mathrm{B}) \cap \mathrm{P}(\mathrm{C})=\mathrm{P}(\mathrm{A}) \cdot \mathrm{P}(\mathrm{B}) \cdot \mathrm{P}(\mathrm{C})
$$

where the cave-in accident takes place when the triggering event or the enabling event or the procedural event occurs. The OR gate is used in such case as a logical operator to link the three basic events. Assuming that all events are statistically independent, the probability of the top undesired event (cave-in accident) can be calculated as follows:

$$
\begin{gathered}
\mathrm{P}(\mathrm{Top})=\mathrm{P}(\mathrm{A}) \mathrm{UP}(\mathrm{B}) \mathrm{UP}(\mathrm{C}) \\
=\mathrm{P}(\mathrm{A})+\mathrm{P}(\mathrm{B})+\mathrm{P}(\mathrm{C})-\mathrm{P}(\mathrm{A} \cap \mathrm{B})-\mathrm{P}(\mathrm{A} \cap \mathrm{C})-\mathrm{P}(\mathrm{B} \cap \mathrm{C})+\mathrm{P}(\mathrm{A} \cap \mathrm{B} \cap \mathrm{C})
\end{gathered}
$$

where a basic event triggers the top undesired event (cave-in accident) if its occurrence is conditioned on the occurrence of another event. In this case, a conditional failure occurs. In such conditional occurrences, an INHIBIT gate is used. When an INHIBIT gate is used to link basic events, the top undesired event occurs if all basic events occur and an additional conditional event occurs. Assuming that all events are statistically independent, the probability of the top undesired even cave-in accident is calculated as follows:

$$
\mathrm{P}(\mathrm{Top})=\mathrm{P}(\mathrm{A}) \cdot \mathrm{P}(\mathrm{B} / \mathrm{A})
$$

A computer model of probabilistic fault-tree analysis has been constructed using Visual Basic. The computer model calculates the probability of the top undesired event (cave-in accident) as a result of different factors. Triggering, enabling and

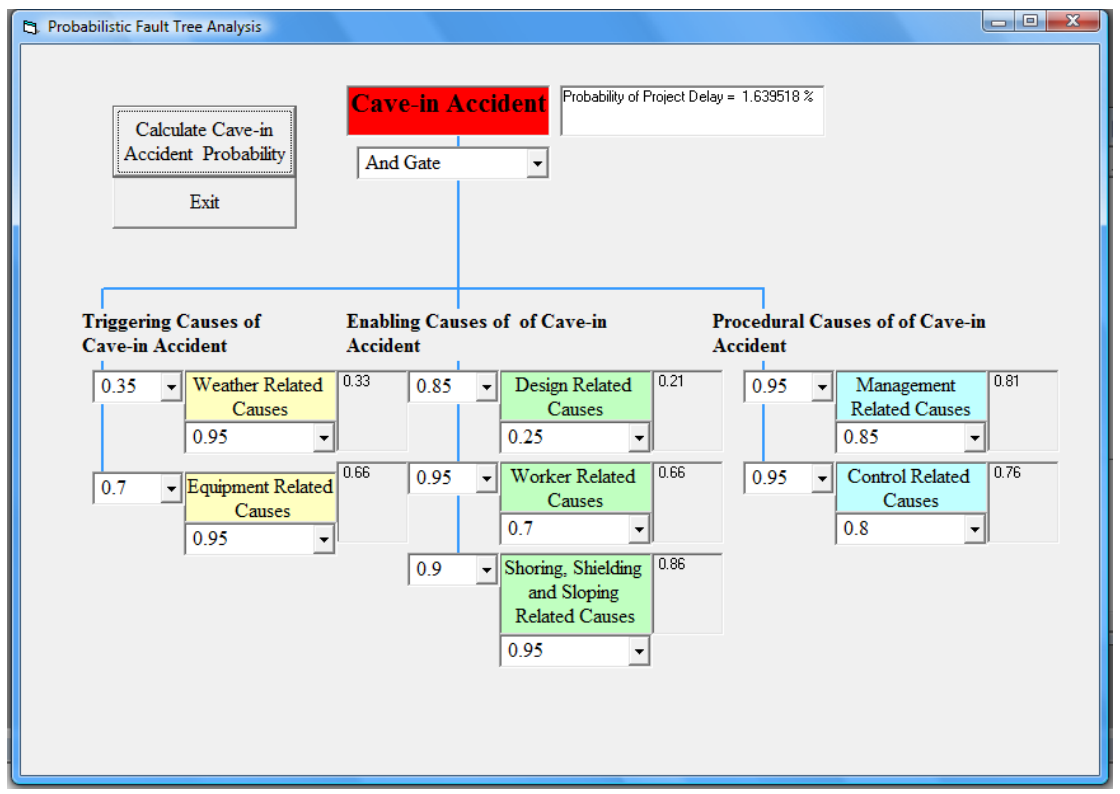

Figure 2: $\quad$ Probabilistic fault tree using and gate. 


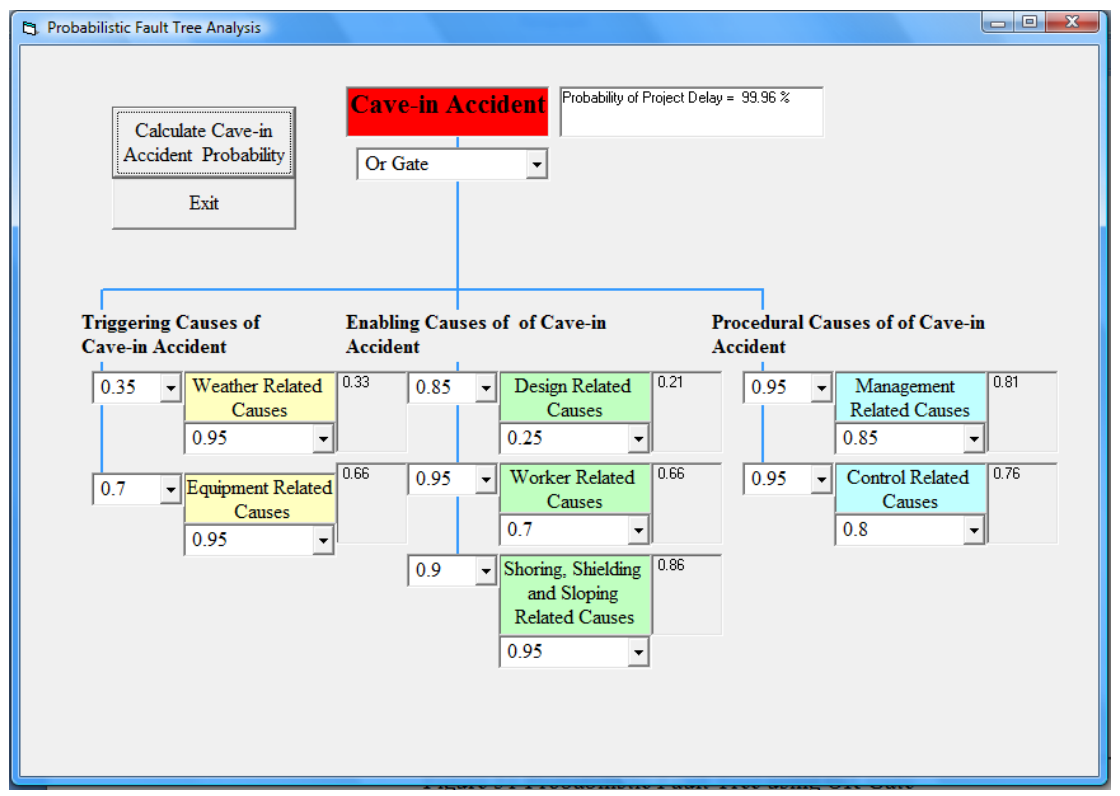

Figure 3: $\quad$ Probabilistic fault tree using or gate.

procedural causes have been implemented to quantify the likelihood of the top undesired event (cave-in accident). Two logical gates (AND and OR gates) have been implemented to link the basic events leading to cave-in accidents. Figs. 2 and 3 show the probabilistic fault-tree computer model using these two logical gates.

Implementation of probabilistic fault-tree analysis to assess the likelihood of cave-in accidents is of questionable value for many reasons. First, the probabilistic fault-tree analysis is based on historical data. Cave-in accidents are unique and unprecedented where uncontrollable factors govern the likelihood of events occurring. Second, the assumption in fault-tree analysis is that all basic events are independent. The different factors that contribute to cave-in accidents are, in fact, statistically dependent. Furthermore, on construction sites, probabilistic values are often expressed subjectively in linguistic terms. Transferring linguistic terms into quantitative probability values is difficult, making implementation of probabilistic fault-tree analysis in such cases questionable. Moreover, since traditional fault-tree analysis is based on Boolean algebra, no partial states are considered. In probabilistic fault-tree analysis, once an event takes place, it triggers the occurrence of the upper-level event. Partial contribution of basic events to upper-level events is not considered. Limitations in implementation of probability theory and the use of linguistic expressions point to a need to develop a fault-tree analysis able to accommodate such issues.

Zadeh [5] introduced the use of fuzzy-set concepts to handle linguistic expressions mathematically. Several models can be used to represent the Boolean linguistic values mathematically. This study follows the nondeterministic fuzzy set approach that uses subjective appraisal and qualitative 
data. A fuzzy-set is created to transform linguistic terms into mathematical representations using a triangular model. This approach is helpful in assessing the likelihood of cave-in accidents.

In order to develop a fault-tree analysis that accommodates the above problems, the fault-tree analysis is modified by implementing the AND, OR, and FUZZY MEAN gates and the fuzzy set concept is introduced.

\section{Fuzzy fault-tree analysis}

Probabilistic risk assessment has been widely implemented to provide predictive analysis when historical data is available. Evaluation of the occurrence of a top event using crisp values without considering the inherent uncertainty and imprecision of each basic event is unrealistic. Fuzzy set theory can be used to deal with this kind of problem.

Interpretation of cave-in accidents is both quantitative and qualitative in its nature. Quantitative analysis of cave-in accidents involves probabilistic assessment methods and probability theory to quantify the possibility of cave-in accident. Probability distribution along with data and information are vital to performing such quantitative assessment analyses. The qualitative aspects of cave-in accidents are expressed subjectively and contain many uncertainties, especially when assessing causes of cave-in accidents and the degree of effectiveness of these causes. The cave-in accident, with all its inherent uncertainty, is a prime candidate for applying fuzzy logic. A method employing a fuzzy fault-tree to represent likelihood of cave-in accident membership functions for a set of fuzzy values has been developed. The method addresses subjective, qualitative and quantitative uncertainties involving the estimation of the likelihood of a cave-in accident.

A fuzzy fault-tree algorithm was developed by the $\alpha$-cut method. The $\alpha$-cut of fuzzy set $\mathrm{A}$ is the crisp set that contains all the elements of the universal set $\mathrm{X}$ whose membership grades in $A$ are greater than or equal to the specified value of alpha. $\alpha$-cut of the membership function A (denoted aA) is the set of all $\mathrm{x}$ such that $\mathrm{A}(\mathrm{x})$ is greater than or equal to alpha (a) [2]. Mathematically,

$$
\mathrm{aA}=\{\mathrm{x} \mid \mathrm{A}(\mathrm{x}) \geq \mathrm{a}\}
$$

Fuzzification is the process of converting crisp, deterministic values into fuzzy and uncertain values [3]. If vagueness and imprecision are inherent, then the variable is fuzzy. When vagueness and imprecision are present, linguistic terms can be used to describe such uncertainty.

In order to capture different causes of cave-in accidents and their degree of effectiveness on the overall likelihood of a cave-in accident, the $\alpha$-cut method is implemented on various fuzzy logic models. At every $\alpha$ level, fuzzy arithmetic can be implemented by multiplying two intervals to capture the condition state (cause of cave-in accident) and the effectiveness of the cause on the overall likelihood of a cave-in accident. The multiplication rule is applied to two intervals as multiplication is performed on an infinite number of combinations of pairs of crisp singletons from each of the two intervals. An interval is expected as a result. 
In triangular fuzzy sets, closed intervals representing the degree of belief of the linguistic terms are determined for both the condition state (cause of cave-in accident) and its effectiveness on the overall likelihood of a cave-in. For example, if weather conditions are bad (negative) and this triggering cause of cave-in accidents is fairly effective (negatively effective) on the overall likelihood of a cave-in, then this information is captured using the alpha-cut ( $\alpha$-cut) method to represent the degree of belief of the linguistic terms for both the cause of a cave-in and its degree of effectiveness on the overall likelihood of a cave-in accident. To capture information on the cause of a cave-in accident and its degree of effectiveness on the overall likelihood of a cave-in, fuzzy multiplication is suggested at each $\alpha$ level.

In fuzzy fault-trees, the likelihood of the top event is based on lower-level events, which are the basic events that are determined by expert opinions and subjective judgments. Basic events are linked via logic symbols (gates) to one or more undesirable top events [1]. In general, three fuzzy gates can be implemented to link basic events. The AND gate is used to indicate that the output occurs if and only if all the input events occur. The OR gate is used to indicate that the output occurs if and only if at least one of the input events occur. The FUZZY MEAN gate obtains the average value of all contributing events.

In general, fuzzy set operations are the standard intersection and the standard union. The weighted average or the fuzzy mean is another operation on fuzzy sets. The following section describes these fuzzy set operations in further detail.

Standard Intersection $(\mathrm{A} \cap \mathrm{B})(\mathrm{x})=\min [\mathrm{A}(\mathrm{x}), \mathrm{B}(\mathrm{x})]$

Standard Union

$$
(\mathrm{AUB})(\mathrm{x})=\max [\mathrm{A}(\mathrm{x}), \mathrm{B}(\mathrm{x})]
$$

Weighted Average (Fuzzy Mean) $(A \sim B)(x)=\left[w_{a} \cdot A(x), w_{b} \cdot B(x)\right] ; w_{a}+w_{b}=1$

Defuzzification is the conversion of fuzzy membership functions into a crisp (discrete) quantity [3]. Defuzzification is the opposite of fuzzification, which is the conversion of a precise quantity into a fuzzy quantity. Many methods are suggested in the literature [3]; among these methods is the center-of-area method.

The center-of-area method, sometimes called the center-of-gravity method or centroid method is used to convert the membership function into a crisp (deterministic) value. $Z^{*}$ is defined as the value for which the area under the graph of the membership function $C$ is divided into two equal sub areas [3]. The value $\mathrm{Z}^{*}$ is calculated using the following formula:

$$
\mathrm{Z}^{*}=\int \mathrm{C}(\mathrm{z}) \cdot \mathrm{zdz} / \int \mathrm{C}(\mathrm{z}) \mathrm{dz}
$$

\section{Illustration}

A computer program was developed to implement the fuzzy fault-tree model, following the above discussion. The following screenshots illustrate fuzzy faulttree analysis using hypothetical values for different causes of cave-in accidents. 


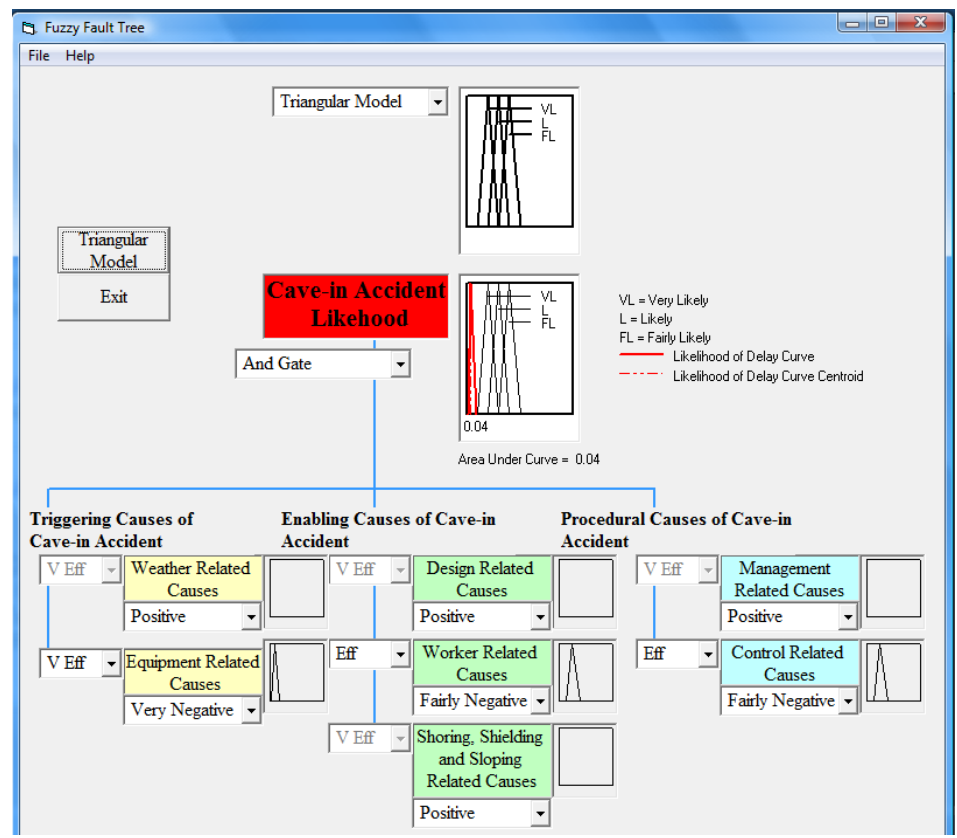

Figure 4: Likelihood of cave-in accident with fuzzy and operation.

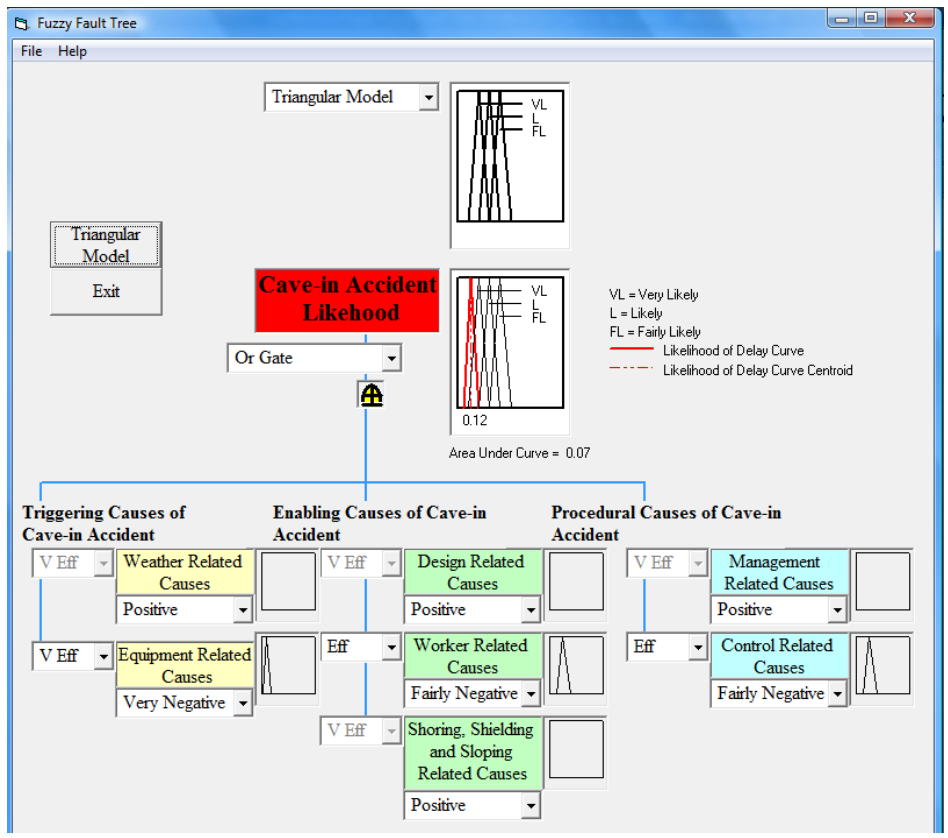

Figure 5: Likelihood of cave-in accident with fuzzy or operation. 


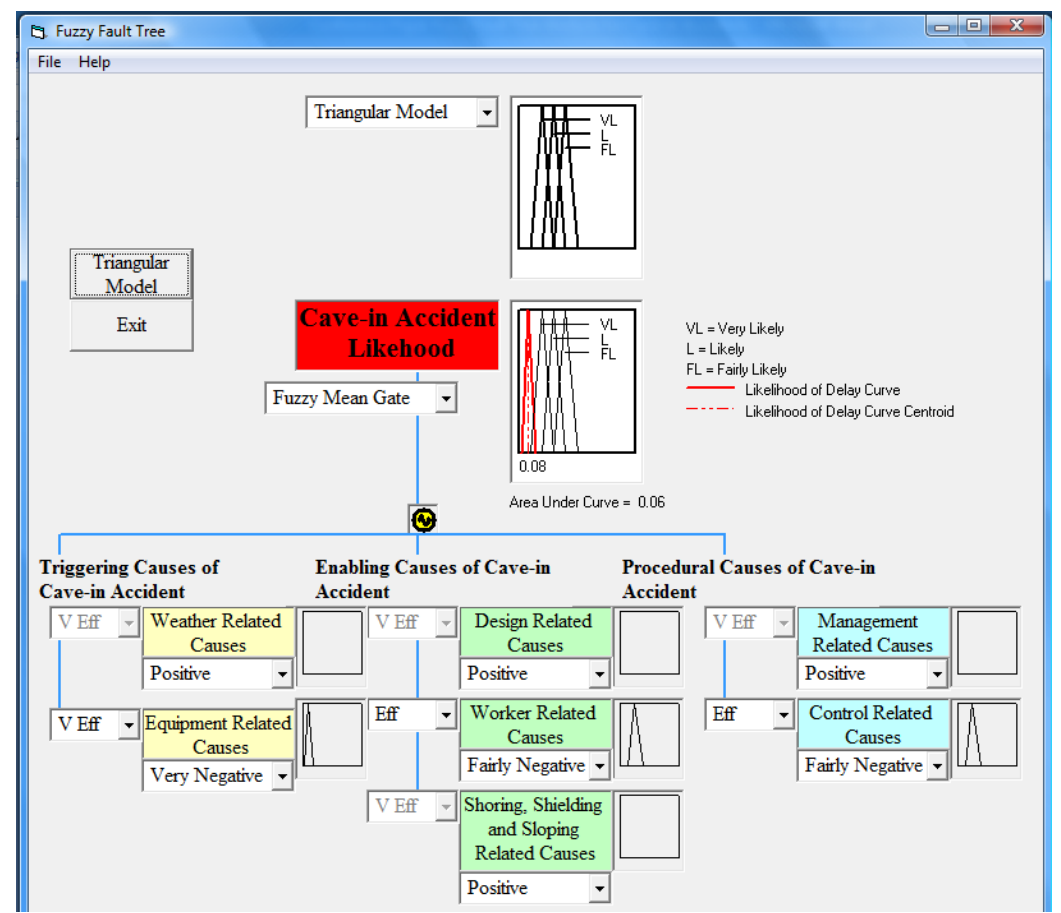

Figure 6: Likelihood of cave-in accident with FUZZY MEAN operation.

\section{Conclusion}

Classification of the causes of cave-in accidents is introduced in this study. Causes of cave-ins are classified into procedural, triggering and enabling causes. Procedural causes are related to management actions and strategies that impact other causes of cave-in accident such as triggering causes and enabling causes. Procedural accident causes are hidden events that produce both triggering and enabling causes. Triggering causes are external to the project such as weather conditions, natural disasters, and unforeseen environmental conditions. Enabling causes are internal to the project, such as material-related causes, worker-related causes and equipment-related causes.

Probabilistic fault-tree analysis is based on interpretation of historical data. Implementation of probabilistic fault-tree analysis for construction projects is of questionable value for many reasons. One reason is that projects are unique in their nature; each project presents a new challenge to management, and implementation of historical data into unprecedented projects is of questionable value. Another reason is that managers use linguistic terms to express opinions about causes of cave-in accidents and the effectiveness of those causes on the likelihood of a cave-in. Quantification of such linguistic terms using probabilistic fault-tree analysis is difficult. Furthermore, probabilistic fault-tree analysis does not include partial states where implementation of a basic event into the fault- 
tree analysis indicates the full contribution of these basic events to the upperlevel event of the analysis. In actual projects, the effectiveness of every event relative to the upper-level event is needed to perform the analysis. Therefore, implementation of the probabilistic fault-tree analysis is of limited value.

The fuzzy fault-tree analysis is introduced here as a method to analyze the likelihood of cave-in accidents using fuzzy logic models. The alpha-cut method ( $\alpha$-cut method) captures the cause of the cave-in accident and its effectives on the likelihood of an accident. In the triangular fuzzy logic model, trigonometric properties capture the various causes of cave-in accidents and their effectiveness on the likelihood of a cave-in. The triangular model is implemented in the fuzzy fault-tree analysis using a computer program that models different causes contributing to cave-in accidents, and the likelihood of a cave-in is assessed using a membership function. The membership function is quantified using the centroid method.

The strength of the triangular model lies in the fact that this model is very clear and easy to interpret. Furthermore, assessment of the degree of likelihood of a cave-in to occur is determined by the horizontal shift of the likelihood of accident membership value. If the likelihood of accident membership function shifts to the left, this is an indication that the set of input values (causes of cavein accident and their effectiveness) are critical, and management needs to take action to prevent a cave-in accident. If the likelihood of cave-in accident membership function shifts to the right, this is an indication that the set of input values (causes of cave-in accident and their effectiveness) are in better condition than before and that management actions are minimizing the likelihood of a cave-in accident. Furthermore the triangular model provides flexibility in the membership functions for causes of cave-in accidents, because the triangular model requires a range of input values by experts to determine the membership function. The flexibility of the triangular model is not implemented into the fuzzy fault-tree computer program developed for this study because the very negative, negative and fairly negative membership functions are fixed in the model and flexibility can be added in future research.

\section{References}

[1] Al-Humaidi, H. M. A fuzzy logic approach to model delays in construction projects, Doctoral of Philosophy Dissertation, The Ohio State University, 2007.

[2] Klir, G., and Yuan, B. Fuzzy Sets and Fuzzy Logic: Theory and Applications, Prentice-Hall, Upper Saddle River, NJ, 1995.

[3] Ross, T., Fuzzy Logic with Engineering Applications, Wiley, 2004.

[4] Vargas C. A, and Hadipriono, F. C. A fault-tree model for falls from a form scaffolding. Proc., First International Conference of CIB Working Commission, pp 195-201.

[5] Zadeh, L. A. Fuzzy sets. Information Control, 8, pp 338-353, 1965. 